\title{
Identification and genotyping of bacteria from paired vaginal and rectal samples from pregnant women indicates similarity between vaginal and rectal microflora
} Nabil Abdullah El Aila ${ }^{\dagger 1}$, Inge Tency ${ }^{\dagger 2}$, Geert Claeys ${ }^{1}$, Hans Verstraelen ${ }^{2}$, Bart Saerens1, Guido Lopes dos Santos Santiago1, Ellen De Backer 1, Piet Cools ${ }^{1}$, Marleen Temmerman ${ }^{2}$, Rita Verhelst ${ }^{\dagger 1}$ and Mario Vaneechoutte*†1

Address: ${ }^{1}$ Laboratory Bacteriology Research, Department of Clinical Chemistry, Microbiology \& Immunology, University of Ghent, Ghent, Belgium and 2Department of Obstetrics \& Gynaecology, Ghent University Hospital, University of Ghent, Ghent, Belgium

Email: Nabil Abdullah El Aila - Nabil.ElAila@UGent.be; Inge Tency - Inge.Tency@UGent.be; Geert Claeys - Geert.Claeys@UGent.be; Hans Verstraelen - Hans.Verstraelen@UGent.be; Bart Saerens - BartSaerens@gmail.com; Guido Lopes dos Santos Santiago - Guido.LopesdosSantosSantiago@Ugent.be; Ellen De Backer - ellekendb@yahoo.com; Piet Cools - Piet.Cools@UGent.be; Marleen Temmerman - Marleen.Temmerman@UGent.be; Rita Verhelst - Rita.Verhelst@UGent.be;

Mario Vaneechoutte* - Mario.Vaneechoutte@UGent.be

* Corresponding author †Equal contributors

Published: 14 October 2009

BMC Infectious Diseases 2009, 9:167 doi:10.1186/147/-2334-9-167

This article is available from: http://www.biomedcentral.com/l47/-2334/9/167

(C) 2009 El Aila et al; licensee BioMed Central Ltd.

This is an Open Access article distributed under the terms of the Creative Commons Attribution License (http://creativecommons.org/licenses/by/2.0), which permits unrestricted use, distribution, and reproduction in any medium, provided the original work is properly cited.
Received: 29 May 2009

Accepted: 14 October 2009

\begin{abstract}
Background: The vaginal microflora is important for maintaining vaginal health and preventing infections of the reproductive tract. The rectum has been suggested as the major source for the colonisation of the vaginal econiche.

Methods: To establish whether the rectum can serve as a possible bacterial reservoir for colonisation of the vaginal econiche, we cultured vaginal and rectal specimens from pregnant women at 35-37 weeks of gestation, identified the isolates to the species level with tRNA intergenic length polymorphism analysis (tDNA-PCR) and genotyped the isolates for those subjects from which the same species was isolated simultaneously vaginally and rectally, by RAPD-analysis.
\end{abstract}

One vaginal and one rectal swab were collected from a total of each of I32 pregnant women at 3537 weeks of gestation. Swabs were cultured on Columbia CNA agar and MRS agar. For each subject 4 colonies were selected for each of both sites, i.e. 8 colonies in total.

Results: Among the 844 isolates that could be identified by tDNA-PCR, a total of 63 bacterial species were present, $9(14 \%)$ only vaginally, $26(41 \%)$ only rectally, and $28(44 \%)$ in both vagina and rectum. A total of $|2|$ (9I.6\%) of I 32 vaginal samples and $5 \mid$ (38.6\%) of I32 rectal samples were positive for lactobacilli. $L$. crispatus was the most frequently isolated Lactobacillus species from the vagina ( $40 \%$ of the subjects were positive), followed by $L$. jensenii $(32 \%)$, L. gasseri (30\%) and $L$. iners (I I\%). L. gasseri was the most frequently isolated Lactobacillus species from the rectum (I5\%), followed by L. jensenii (I2\%), L. crispatus (II\%) and L. iners ( $2 \%$ ).

A total of 47 pregnant women carried the same species vaginally and rectally. This resulted in $\mathbf{5 0}$ vaginal/rectal pairs of the same species, for a total of eight different species. For 34 of the 50 species 
pairs (68\%), isolates with the same genotype were present vaginally and rectally and a high level of genotypic diversity within species per subject was also established.

Conclusion: It can be concluded that there is a certain degree of correspondence between the vaginal and rectal microflora, not only with regard to species composition but also with regard to strain identity between vaginal and rectal isolates.

These results support the hypothesis that the rectal microflora serves as a reservoir for colonisation of the vaginal econiche.

\section{Background}

The composition of the human vaginal microflora is affected by several host factors, including, among others, age, menarche, sexual activity, pregnancy and the use of contraceptives or spermicides, as well as individual habits such as douching [1]. Several bacterial species are known to colonize both the gastrointestinal and the reproductive tract, and the rectum has been suggested to play an important role as a source or reservoir for organisms that colonize the vagina $[2,3]$. It is important to establish to which degree this is also the case for lactobacilli, the predominant group of microorganisms of the normal vaginal microflora, because these bacteria are generally known to produce endogenous microbicides such as lactic acid, which acidifies the vagina, and hydrogen peroxide $\left(\mathrm{H}_{2} \mathrm{O}_{2}\right)$, toxic to other bacteria and viruses, including HIV [4]. Studies of vaginal lactobacilli have demonstrated that L. crispatus, L. jensenii, L. gasseri and L. vaginalis are the most commonly recovered species of $\mathrm{H}_{2} \mathrm{O}_{2}$-producing lactobacilli [5-9] and the absence of $\mathrm{H}_{2} \mathrm{O}_{2}$-producing lactobacilli in the vagina has been associated with an increased risk for bacterial vaginosis (BV) $[10,11]$. BV has been linked to increased shedding of HIV in the female genital tract [12], increased acquisition of HIV [10] and herpes simplex virus type $2[10,12]$ and with preterm birth [13].

In order to document in more detail a possible rectal origin of the vaginal microflora, this study was set up not only to compare the bacterial species present in vagina and rectum, but in addition, to compare the genotypes of those strains belonging to species that were present simultaneously at both sampling sites of the same subject.

\section{Methods}

\section{Patients}

The study was approved by the research ethics committee (IRB protocol nr 2007/096) of Ghent University Hospital, Belgium. All women attending the clinic were included and participating women gave a written informed consent. Between April and December 2007, 132 paired vaginal and rectal swabs were collected from pregnant women at 35 - 37 weeks of gestation.

\section{Sampling procedures}

All specimens were collected using nylon flocked swabs that were submerged into $1 \mathrm{ml}$ of liquid Amies transport medium (eSwab, Copan Diagnostics, Brescia, It.). For rectal specimens, a swab was carefully inserted approximately 1.5 - $2 \mathrm{~cm}$ beyond the anal sphincter and then gently rotated to touch anal crypts.

Vaginal samples were collected by inserting a swab into the vagina. The swab was rolled round through 360 degrees against the vaginal wall at the midportion of the vault. At Ghent University Hospital, the routine screening for group B streptococci of pregnant women is always performed during the prenatal consultation at 35-37 weeks' gestation according to the CDC guidelines for the prevention of perinatal Group B streptococcal disease [14]. All study samples were collected by midwives and transported to the Laboratory for Bacteriology Research of the University of Gent within 4 hours.

\section{Culture and Gram staining}

A total of $70 \mu \mathrm{l}$ from the Amies liquid transport medium of each of the vaginal and rectal swabs was inoculated onto Columbia CNA agar with 5\% sheep blood (Columbia CNA agar, Becton Dickinson, Erembodegem, Belgium) respectively De Mann Rogosa Sharp Agar (MRS, Oxoid, Hampshire, UK) and then incubated at $37^{\circ} \mathrm{C}$ in an anaerobic chamber $\left(10 \% \mathrm{H}_{2}, 10 \% \mathrm{CO}_{2}, 80 \% \mathrm{~N}_{2}\right.$ ) (BugBox, LedTechno, Heusden-Zolder, B.) for 72 h. Another $50 \mu$ of the vaginal swab suspension was taken for smear preparation for the Gram stain.

Gram stain based grading was carried out according to modified Ison \& Hay criteria [15], as described by Verhelst et al. [16].

Grade Ia specimens contained mainly Lactobacillus crispatus cell types, i.e. plump, quite homogeneous lactobacilli, grade Ib contained non-L. crispatus cell types, i.e. long or short, thin lactobacilli, grade Iab contained mixtures of $L$. crispatus and non-L. crispatus cell types, grade I-like contained irregular-shaped Gram positive rods, grade II contained a mixture of Lactobacillus cell types and bacterial 
vaginosis-associated bacteria (Gardnerella, BacteroidesPrevotella and Mobiluncus cell types), whereas samples devoid of Lactobacillus cell types with the presence of only Gardnerella, Bacteroides- Prevotella or Mobiluncus cell types were classified as grade III. Finally, samples were classified as grade IV when Gram positive cocci were predominantly present and as grade 0 when no bacterial cells were present [16].

\section{DNA-extraction from isolates}

DNA was extracted from cultured isolates by alkaline lysis as follows: One bacterial colony was suspended in $20 \mu \mathrm{l}$ of lysis buffer $(0.25 \%$ sodium dodecyl sulfate, $0.05 \mathrm{~N}$ $\mathrm{NaOH}$ ) and heated at $95^{\circ} \mathrm{C}$ for $15 \mathrm{~min}$. The cell lysate was diluted by adding $180 \mu \mathrm{l}$ of distilled water. The cell debris was spun down by centrifugation at $16,000 \mathrm{~g}$ for $5 \mathrm{~min}$. Supernatants were used for PCR or frozen at $-20^{\circ} \mathrm{C}$ until further use.

\section{Identification of isolates}

From all 132 women, 8 colonies per subject, i.e., one colony of each of the two most abundant colony types from both Columbia CNA and MRS agar plates and for both rectal and vaginal swabs were picked, i.e. a total of 1056 isolates. Isolates were identified by tRNA intergenic length polymorphism analysis (tDNA-PCR) as described before [8,17-19]. Briefly, the tRNA-intergenic spacer regions were amplified by PCR using consensus primers, applicable to most bacterial species, and the resulting fingerprints, obtained by separation of the amplified spacers by capillary electrophoresis on an ABI310, were compared with those of a large library of reference strains of the different species, shown in previous studies to be part of the vaginal microflora. Isolates with fingerprints that did not match fingerprints already present in the library were considered as not identifiable.

\section{Genotyping of isolates}

Isolates of species present in both vagina and rectum of the same subject were genotyped using RAPD-analysis with RAPD Ready-to-Go beads (GE Healthcare, Buckinghamshire, UK) as described previously [20] with primer OPM1 (5' GTT GGT GGC T) at a final concentration of 2 $\mu \mathrm{M}$, including $0.2 \mu \mathrm{M}$ of fluorescent TET-labeled OPM1 primer. After $5 \mathrm{~min}$ at $94^{\circ} \mathrm{C}, 5 \mathrm{~min}$ at $35^{\circ} \mathrm{C}$ and $5 \mathrm{~min}$ at $72^{\circ} \mathrm{C}$, reaction mixtures were cycled 30 times in a Veriti ${ }^{\mathrm{TM}}$ Thermal Cycler (Applied Biosystems, Foster City, Ca.), with the following conditions: $30 \mathrm{~s}$ at $94^{\circ} \mathrm{C}, 1 \mathrm{~min}$ at $35^{\circ} \mathrm{C}$, and $1 \mathrm{~min}$ at $72^{\circ} \mathrm{C}$, with a final extension period of $5 \mathrm{~min}$ at $72^{\circ} \mathrm{C}$. Reaction vials were then cooled to $10^{\circ} \mathrm{C}$ until electrophoresis.

\section{Capillary electrophoresis}

A volume of $11.9 \mu \mathrm{l}$ of deionized formamide (ACE formamide, Lucron, De Pinte) was mixed with $0.6 \mu$ l of an inter- nal size standard mixture containing $0.3 \mu \mathrm{l}$ of the ROX400 high-density size standard (Applied Biosystems, Foster City, Ca.) and $0.3 \mu \mathrm{l}$ of Map marker 1000 size standard (BioVentures, Murfreesboro, Tn.). One $\mu$ l of RAPD-PCR product was added. The mixtures were denatured by heating at $95^{\circ} \mathrm{C}$ for $3 \mathrm{~min}$ and placed directly on ice for at least $10 \mathrm{~min}$. Capillary electrophoresis was carried out using an ABI-Prism 310 genetic analyzer (Applied Biosystems) at $60^{\circ} \mathrm{C}$, at a constant voltage of $1.5 \mathrm{kV}$, and at a more or less constant current of approximately $10 \mathrm{~mA}$. Capillaries with a length of $47 \mathrm{~cm}$ and diameter of $50 \mu \mathrm{m}$ were filled with performance-optimized polymer 4. Electropherograms were normalized using Genescan Analysis software, version 2.1 (Applied Biosystems).

\section{Data analysis}

tDNA-PCR and RAPD fingerprints were obtained as table files from the GeneScan Analysis software (Applied Biosystems) and analyzed with BaseHopper, an in house software program [17]. The obtained tDNA fingerprints were compared with those of a library of tDNA fingerprints obtained from reference strains, representing most vaginal species isolated in previous studies and previously identified by $16 \mathrm{~S}$ rRNA gene sequencing [8].

Similarity between RAPD fingerprints was calculated using the Dice algorithm. Clustering analysis was done with the Neighbor module of the Phylip software http:// evolution.genetics.washington.edu/phylip.html, using the Neighbour joining algorithm. Isolates of which the RAPD fingerprints were clustered together, were inspected visually to confirm similarity.

\section{Results \\ Categorization of vaginal microflora}

Samples were categorized as grade Ia for 55 subjects (41.6\%), grade Ib for $37(28.0 \%)$, grade Iab for 13 $(9.8 \%)$, grade I-like for 5 (3.8\%), grade II for $14(10.6 \%)$, grade III for $6(4.5 \%)$ and grade 0 for $2(1.5 \%)$.

The most common genus recovered from grade Ia, Ib and Iab specimens was Lactobacillus. Grade Ia samples contained predominantly L. crispatus $(75.0 \%)$ and L. jensenii (43.6\%), whereas L. gasseri (40.5\%) and L. iners (27\%) were the most frequently present species in grade Ib specimens. The five grade I-like specimens were found to contain respectively Bifidobacterium bifidum and Enterococcus faecalis, L. gasseri and E. faecalis, L. jensenii, L. gasseri and Gardnerella vaginalis or L. rhamnosus.

The most characteristic cultured organisms in grade II and grade III specimens were G. vaginalis (28\% and 33\%, respectively), Actinomyces neuii, Aerococcus christensenii, Atopobium vaginae and Finegoldia magna. The lactobacilli cultured from the six grade III specimens were respectively 
L. iners, L. gasseri, L. jensenii, L. crispatus, L. rhamnosus and a combination of L. gasseri and L. vaginalis.

\section{Rectal and vaginal prevalence of different bacterial species}

For a total of 132 women, 4 colonies each were picked from the vaginal and rectal sites, i.e. a total of 1056 colonies were picked and subjected to identification by tDNAPCR. Of these, 844 could be identified.

A total of 103 isolates gave no amplification or tDNA-PCR patterns composed of only a few and short tRNA intergenic spacers. Most of the isolates for which no amplification or only a few fragments could be obtained, are probably corynebacteria, which yield poor tDNA-PCR fingerprints (unpublished data).

Finally, 109 isolates gave uninterpretable patterns, due to mixed cultures, as was confirmed by $16 \mathrm{~S}$ rRNA gene sequencing for 20 of these, whereby the sequences could not be interpreted because of ambiguities, pointing to mixtures.

The frequency of vaginal and rectal colonization by lactobacilli and the other most prominent bacterial species is shown in Table 1 . A total of 63 bacterial species were identified, 9 (14\%) occurring only vaginally, 26 (41\%) only rectally and $28(44 \%)$ in both vagina and rectum, with 8 species that could be isolated simultaneously from rectum and vagina of 47 subjects.

Overall, 121 of 132 pregnant women (92\%) carried vaginal lactobacilli and 52 (39\%) carried rectal lactobacilli. Seventy two pregnant women (54.5\%) carried lactobacilli only vaginally, three only rectally (2\%) and $49(37 \%)$ in both sites, i.e. only three women out of 52 from whom lactobacilli could be isolated rectally, did not carry lactobacilli vaginally. L. crispatus was the most frequently identified Lactobacillus species isolated from the vagina $(40 \%$, i.e., 53/132 subjects positive of which 10 also carried $L$. crispatus rectally), followed by L. jensenii (32\%), L. gasseri $(30 \%)$, L. iners (11\%) and L. vaginalis (10\%).

Besides these five Lactobacillus species, all other species were encountered in no more than five subjects, except for G. vaginalis ( $8 \%$ of subjects positive).

L. gasseri was the most frequently isolated Lactobacillus species from the rectum (20/132 subjects positive), followed by L. jensenii (16) and L. crispatus (14). L. iners was isolated rectally from only 2 subjects. L. vaginalis was isolated only from the vagina, whereas L. fermentum, L. coleohominis and L. fermentum were only isolated from the rectum, at a frequency of $\leq 1 \%$. Rectally, the most abundant species that could be cultured, were Streptococcus anginosus group (47/132 subjects positive), Finegoldia magna (40), Peptoniphilus indolicus (25) and E. faecalis (21).

Fourty six pregnant women (35\%) were colonized by at least 2 different Lactobacillus species, with 42 of them only vaginally, two only rectally and another two both in the vagina and rectum. Taking into account vaginal and rectal colonization by more than one Lactobacillus species, 18 women $(13.6 \%)$ were colonized by both L. crispatus and L. jensenii, of which 17 vaginally and one rectally, five (4\%) by L. jensenii and L. gasseri of which 3 vaginally and 2 rectally and another $18(13.6 \%)$ with other combinations of Lactobacillus species. Seven subjects (5.3\%) were colonized vaginally by more than two Lactobacillus species. In total, of the 121 women colonized vaginally by lactobacilli, 42 (32\%) were colonized by two or more Lactobacillus species and of the 52 women colonized by lactobacilli rectally, two (1.5\%) were colonized by two Lactobacillus species. A total of 47 (35\%) of 132 pregnant women were colonized both vaginally and rectally with the same species and 3 of these 47 women carried two species both vaginally and rectally. The species found to be simultaneously present in the same subject both rectally and vaginally were $L$. crispatus ( $\mathrm{n}=10$ subjects), L. jensenii (14), L. gasseri (16), S. anginosus (3), S. agalactiae (3), S. salivarius (1), E. faecalis (2) and Bifidobacterium species (1). In summary, $50 \mathrm{vaginal} / \mathrm{rectal}$ pairs of the same species were observed in 47 subjects, for a total of eight different species.

\section{Genotyping of bacterial isolates from the vagina and the rectum}

For 34 of the 50 vaginal/rectal species pairs, isolates with the same genotype were present vaginally and rectally.

Table 2 presents the genotyping results for each of the 50 vaginal/rectal species pairs. We found the same genotype for both rectal and vaginal $L$. crispatus isolates in 7/10 subjects, for L. gasseri in 14/16, for L. jensenii in 7/14, for Bifidobacterium species in $1 / 1$, for $E$. faecalis in $1 / 2$, for $S$. agalactiae in 2/3, and for $S$. anginosus in $2 / 3$.

Figure 1 shows the genotyping results for four pregnant women for which rectal and vaginal isolates belonged to a single genotype, for L. gasseri (Figure 1), L. crispatus (Figure 2), L. jensenii (Figure 3) and E. faecalis (Figure 4).

\section{Genotyping results: variability among multiple isolates per subject}

For only 2 of the 9 vaginal samples of which more than one L. crispatus isolate was picked, all the isolates belonged to the same genotype. For the 7 other vaginal samples, 2 to 3 genotypes of L. crispatus were present. In 7 of the 10 cases for which rectal/vaginal pairs of L. crispatus 
Table I: Vaginal and rectal prevalence of 63 bacterial species among I 32 pregnant women

\begin{tabular}{|c|c|c|c|c|c|}
\hline & Species & $\begin{array}{c}\text { Only } \\
\text { vaginala }^{a}\end{array}$ & Only rectal & Vaginal + rectal & Overall \\
\hline I & Acinetobacter baumannii group & 0 & 8 & 0 & 8 \\
\hline 2 & Actinomyces meyeri & 0 & 2 & 0 & 2 \\
\hline 3 & Actinomyces neuii & 2 & 0 & 0 & 2 \\
\hline 4 & Actinomyces radingae & 0 & 1 & 0 & 1 \\
\hline 5 & Actinomyces urogenitalis & 0 & 1 & 0 & 1 \\
\hline 6 & Aerococcus christensenii & 3 & 2 & 0 & 5 \\
\hline 7 & Aerococcus viridans & 0 & 1 & 0 & 1 \\
\hline 8 & Agrobacterium radiobacter & 0 & 2 & 0 & 2 \\
\hline 9 & Alloscardovia omnicolens & 0 & 1 & 0 & $\mathrm{I}$ \\
\hline 10 & Anaerococcus tetradius & 0 & 1 & 0 & 1 \\
\hline 11 & Anaerococcus vaginalis & 0 & 4 & 0 & 4 \\
\hline 12 & Atopobium vaginae & 2 & 2 & 0 & 4 \\
\hline 13 & Bacteroides uniformis & 1 & 1 & 0 & 2 \\
\hline 14 & Bifidobacterium bifidum & 2 & 6 & 1 & 9 \\
\hline 15 & Bifidobacterium longum subsp. longum & 2 & 5 & 0 & 7 \\
\hline 16 & Bifidobacterium longum subsp. infantis & 0 & 2 & 0 & 2 \\
\hline 17 & Bifidobacterium breve & 0 & 1 & 0 & 1 \\
\hline 18 & Corynebacterium accolens & 0 & 1 & 0 & 1 \\
\hline 19 & Dialister sp. & 5 & 0 & 0 & 5 \\
\hline 20 & Enterococcus faecalis & 5 & 19 & 2 & 26 \\
\hline 21 & Enterococcus faecium & 1 & 3 & 0 & 4 \\
\hline 22 & Enterococcus avium & 0 & 1 & 0 & 1 \\
\hline 23 & Escherichia coli & 1 & 7 & 0 & 8 \\
\hline 24 & Finegoldia magna & 2 & 40 & 0 & 42 \\
\hline 25 & Fusobacterium gonidioformans & 0 & 3 & 0 & 3 \\
\hline 26 & Gardnerella vaginalis & 10 & 2 & 0 & 12 \\
\hline 27 & Klebsiella planticola & 0 & 1 & 0 & 1 \\
\hline 28 & Lactobacillus casei & 2 & 1 & 0 & 3 \\
\hline 29 & Lactobacillus fermentum & 1 & 0 & 0 & 1 \\
\hline 30 & Lactobacillus coleohominis & 2 & 0 & 0 & 2 \\
\hline 31 & Lactobacillus crispatus & 43 & 4 & 10 & 57 \\
\hline 32 & Lactobacillus fermentum & 2 & 0 & 0 & 2 \\
\hline 33 & Lactobacillus gasseri & 24 & 4 & 16 & 44 \\
\hline 34 & Lactobacillus helveticus & I & 1 & 0 & 2 \\
\hline 35 & Lactobacillus iners & 14 & 2 & 0 & 16 \\
\hline 36 & Lactobacillus jensenii & 28 & 2 & 14 & 44 \\
\hline 37 & Lactobacillus mucosae & 0 & 1 & 0 & 1 \\
\hline 38 & Lactobacillus rhamnosus & 3 & 3 & 0 & 6 \\
\hline 39 & Lactobacillus salivarius & 1 & 1 & 0 & 2 \\
\hline 40 & Lactobacillus vaginalis & 13 & 0 & 0 & 13 \\
\hline $4 I$ & Lactobacillus coleohominis & 1 & 0 & 0 & 1 \\
\hline 42 & Pediococcus acidilactici & 1 & 0 & 0 & 1 \\
\hline 43 & Peptoniphilus indolicus & 1 & 25 & 0 & 26 \\
\hline 44 & Peptostreptococcus anaerobius & 1 & 4 & 0 & 5 \\
\hline 45 & Peptostreptococcus sp. & 0 & 8 & 0 & 8 \\
\hline 46 & Prevotella bivia & 4 & 2 & 0 & 6 \\
\hline 47 & Pseudomonas stutzeri & 0 & 1 & 0 & 1 \\
\hline 48 & Staphylococcus aureus & 0 & 1 & 0 & 1 \\
\hline 49 & Staphylococcus capitis & 1 & 4 & 0 & 5 \\
\hline 50 & Staphylococcus epidermidis & 3 & 13 & 0 & 16 \\
\hline 51 & Staphylococcus haemolyticus & 2 & 1 & 0 & 3 \\
\hline 52 & Staphylococcus hominis & 1 & 4 & 0 & 5 \\
\hline 53 & Staphylococcus warneri & 0 & 2 & 0 & 2 \\
\hline 54 & Streptococcus agalactiae & 1 & 4 & 3 & 8 \\
\hline 55 & Streptococcus anginosus & 3 & 44 & 3 & 50 \\
\hline 56 & Streptococcus bovis & 0 & 8 & 0 & 8 \\
\hline 57 & Streptococcus intermedius & 0 & I & 0 & 1 \\
\hline 58 & Streptococcus mitis group & 0 & 7 & 0 & 7 \\
\hline 59 & Streptococcus mutans & 1 & 0 & 0 & 1 \\
\hline 60 & Streptococcus parasanguinis & 0 & I & 0 & 1 \\
\hline 61 & Streptococcus salivarius & 3 & 2 & 1 & 6 \\
\hline 62 & Varibaculum cambriense & 0 & 1 & 0 & $\mathrm{I}$ \\
\hline \multirow[t]{2}{*}{63} & Weissella paramesenteroides & 0 & 1 & 0 & 1 \\
\hline & & 193 & 270 & 50 & 513 \\
\hline
\end{tabular}

a: Number of pregnant women carrying this species. 
were observed, the one or two rectal L. crispatus isolates had the same genotype of at least one of the one to four vaginal isolates. For only two of the 11 women for which more than one vaginal $L$. jensenii isolate was present, the genotype of all isolates was identical. For another two of these 11 women, all four isolates were genotypically different. For half $(7 / 14)$ of the subjects with $L$. jensenii, the presence of identical rectal and vaginal isolates could be established.

For the other species, a similar pattern of large heterogeneity among the vaginal strains of the same species was also observed and about half of the women were found to carry at least one vaginal isolate genotypically identical to at least one rectal isolate.

\section{Discussion}

During the last decade, the composition of the vaginal microflora has been well characterised, using culture based and culture independent methods [8,21-27]. However, the origin of lactobacilli and BV associated bacteria remains less well-understood and different opinions exist as to whether the vaginal bacteria are largely endogenous or whether there is continuous recolonizaton from the rectum. Few studies have addressed the species composition of both vagina and rectum in the same subjects $[2,3,5]$ and only the study of Marrazzo et al. [3] genotyped paired rectal/vaginal isolates, from lesbian women. To our knowledge, this is the first study among pregnant women to address the relatedness of vaginal and rectal strains to the degree of clonal identity of the strains.

\section{Rectal and vaginal occurrence of lactobacilli}

Table 3 compares the findings of this study with those of two other groups with respect to rectal and vaginal colonization by lactobacilli. The four species predominant in the vagina, as established in this study, i.e. L. crispatus, L. jensenii, L. gasseri and L. iners are in correspondence with previous studies $[2,3,6,16,28-30]$.

Both Antonio et al. [2] and Marrazzo et al. [3] reported $L$. crispatus and L. jensenii twice as much vaginally compared to their rectal occurrence, whereas we report four, respectively three times higher abundance of these species vaginally. Both groups also found approximately equal abundance for $L$. gasseri in rectum and vagina, whereas we could isolate twice as much $L$. gasseri from the vagina. $L$. iners was found ten times more often vaginally than rectally in this study and 20 times more vaginally than rectally in that of Antonio et al. [2], while this species was virtually absent from the study of Marrazzo et al. [3]. L. vaginalis was not found by Marrazzo et al. [3] and virtually absent in the study of Antonio et al. [2], whereas we found a vaginal carriage rate of approximately $10 \%$.
The differences in Lactobacillus vaginal microflora between studies may be attributed to several factors. One suggestion is that the intestinal lactobacilli differ geographically [5], and the same may be true for the vaginal lactobacilli [31]. Also the populations studied differ, e.g. pregnant women in our study vs. nonpregnant women in the study of Antonio et al. [2] and lesbian women in the study of Marrazzo et al. [3]. Strong differences may exist between women, e.g. on average only $30 \%$ of the women carry $L$. crispatus, differences between Caucasian and black women have been reported [32], and differences may be present for each woman because samples can be taken during different phases of the menstrual cycle. More technically related factors concern variations in the way that samples are taken, transported and treated, the fact that culture media and incubation methods may strongly influence the outcome, e.g. incubation in an anaerobic chamber yields more $L$. vaginalis than incubation in an anaerobic jar (see below) and the use of MRS agar precludes isolation of $L$. iners, and that identification has often been based on phenotypic methods [33,34].

In addition, Kim et al. [35], reported that the vaginal microflora is not homogeneous throughout the vaginal tract but differs significantly within an individual with regard to anatomical site and sampling method used.

Apparently, when based on culture, the vaginal carriage rate for L. crispatus ranges between 20 and 40\% (Antonio et al. [6], Kiss et al. [28], this study), although Marrazzo et al. [3] report a carriage rate of approximately $65 \%$. The high percentage reported by the latter group could be related to the study of a different population (lesbian women), to the use of culture methods better suited for $L$. crispatus and corresponds better with results obtained by non culture based methods, as reported previously $[16,22,26,27,32,36-38]$.

Interestingly, in a previous study of our group [8], we isolated almost no $L$. vaginalis, using anaerobic jars and GasPak (Becton Dickinson), yielding an atmosphere of $15 \% \mathrm{CO}_{2}, 80 \% \mathrm{~N}_{2}$, and less than $1 \% \mathrm{O}_{2}$. Since we started using an anaerobic chamber, with an atmosphere of $10 \%$ $\mathrm{H}_{2}, 10 \% \mathrm{CO}_{2}$, and $80 \% \mathrm{~N}_{2}$, the number of L. vaginalis isolations has increased significantly and this species is now among the five most abundant vaginal species. Possibly, the virtual absence of $L$. vaginalis in the studies of Antonio et al. [2] and Marrazzo et al. [3] might be explained by the use of anaerobic culture in jars.

Comparing the reported culture results for $L$. iners remains also problematic, because this species does not grow on MRS agar, specifically designed to culture lactobacilli, and the small colonies it forms on most media may be more easily overlooked. 
Table 2: Genotyping results for the 50 cases in which the same species could be isolated from vagina and rectum of the same subject

\begin{tabular}{|c|c|c|c|c|c|c|c|c|c|c|}
\hline & Subjects, arranged per species & $\mathbf{V} I^{\mathbf{a}}$ & $\mathbf{V 2}$ & V3 & V4 & $\mathbf{R} \mathbf{I}$ & $\mathbf{R 2}$ & $\mathbf{R 3}$ & $\mathbf{R 4}$ & $\mathbf{V}=\mathbf{R}^{\mathbf{c}}$ \\
\hline & Lactobacillus crispatus & & & & & & & & & \\
\hline I & RVSO03 & $\mathbf{B}^{\mathbf{b}}$ & A & & C & & & $\mathbf{A}$ & & 1 \\
\hline 2 & RVSOII & & & A & $\mathbf{A}$ & & & $\mathbf{A}$ & & 2 \\
\hline 3 & RVSOI3 & & A & B & & & & A & & 3 \\
\hline 4 & RVSO20 & A & & & B & & & & C & \\
\hline 5 & RVS023 & & & $\mathbf{A}$ & B & & & C & & \\
\hline 6 & RVS028 & $\mathbf{A}$ & & & B & & & C & D & \\
\hline 7 & RVS043 & & & $\mathbf{A}$ & & & & A & & 4 \\
\hline 8 & RVS06I & $\mathbf{A}$ & A & A & A & & & & A & 5 \\
\hline 9 & RVS069 & B & A & C & A & & & A & & 6 \\
\hline \multirow[t]{2}{*}{10} & RVS099 & B & & $\mathbf{A}$ & & & & & $\mathbf{A}$ & 7 \\
\hline & Lactobacillus jensenii & & & & & & & & & \\
\hline II & RVSOI5 & B & C & D & A & & A & & & 8 \\
\hline 12 & RVSOI9 & B & A & C & A & D & & $\mathbf{E}$ & & \\
\hline 13 & RVSO22 & & A & A & B & & A & A & & 9 \\
\hline 14 & RVSO23 & & A & & & & & & B & \\
\hline 15 & RVS038 & & A & & B & C & & & & \\
\hline 16 & RVS040 & & $\mathbf{A}$ & B & & & & C & & \\
\hline 17 & RVS057 & B & C & A & A & & & D & & \\
\hline 18 & RVS058 & A & A & & A & B & & & & \\
\hline 19 & RVS080 & A & & B & A & & & B & & 10 \\
\hline 20 & RVS092 & & & & A & & & & A & 11 \\
\hline 21 & RVS093 & A & A & & A & & & & A & 12 \\
\hline 22 & RVS097 & C & A & B & $\mathbf{A}$ & & & A & & 13 \\
\hline 23 & RVSIII & & & & A & & & A & A & 14 \\
\hline \multirow[t]{2}{*}{24} & RVSII3 & & & A & & B & & & & \\
\hline & Lactobacillus gasseri & & & & & & & & & \\
\hline 25 & RVSO24 & & & A & & A & & A & A & 15 \\
\hline 26 & RVSO25 & B & & $\mathbf{A}$ & A & & & C & & \\
\hline 27 & RVSO3I & & A & A & B & & & & C & \\
\hline 28 & RVS035 & A & $\mathbf{A}$ & & & & & A & & 16 \\
\hline 29 & RVS044 & & & A & & & & $\mathbf{A}$ & & 17 \\
\hline 30 & RVS05I & & A & A & & & & A & & 18 \\
\hline 31 & RVS054 & & & A & & & & & $\mathbf{A}$ & 19 \\
\hline 32 & RVS060 & & & A & & A & & & & 20 \\
\hline 33 & RVS072 & & & & $\mathbf{A}$ & & & $\mathbf{A}$ & & 21 \\
\hline 34 & RVS084 & B & & & A & & & & A & 22 \\
\hline 35 & RVS090 & & & $\mathbf{A}$ & $\mathbf{A}$ & & & A & $\mathbf{A}$ & 23 \\
\hline 36 & RVS09I & A & & & $\mathbf{A}$ & & & $\mathbf{A}$ & B & 24 \\
\hline 37 & RVS095 & & B & A & $\mathbf{A}$ & & & & $\mathbf{A}$ & 25 \\
\hline 38 & RVSI09 & & & A & B & & & A & & 26 \\
\hline 39 & RVSIIO & $\mathbf{A}$ & A & B & B & & & B & A & 27 \\
\hline \multirow[t]{2}{*}{40} & RVSI36 & $\mathbf{A}$ & A & A & A & & & A & & 28 \\
\hline & Streptococcus anginosus & & & & & & & & & \\
\hline 41 & RVSO03 & & & A & & B & & & & \\
\hline 42 & RVS058 & & & A & & & A & B & & 29 \\
\hline \multirow[t]{2}{*}{43} & RVS068 & & & & $\mathbf{A}$ & & A & $\mathbf{A}$ & & 30 \\
\hline & Streptococcus agalactiae & & & & & & & & & \\
\hline 44 & RVSO27 & B & & A & & & A & & $\mathbf{A}$ & 31 \\
\hline 45 & RVS064 & A & A & A & A & & & A & & 32 \\
\hline \multirow[t]{2}{*}{46} & RVS076 & & A & & B & C & D & & & \\
\hline & Enterococcus faecalis & & & & & & & & & \\
\hline 47 & RVS086 & $\mathbf{A}$ & A & A & A & $\mathbf{A}$ & A & A & A & 33 \\
\hline \multirow[t]{2}{*}{48} & RVSI22 & & & & B & A & A & & & \\
\hline & Streptococcus salivarius & & & & & & & & & \\
\hline \multirow[t]{2}{*}{49} & RVS075 & & & & A & & & & B & \\
\hline & Bifidobacterium bifidum & & & & & & & & & \\
\hline 50 & RVS033 & A & & & A & & & A & & 34 \\
\hline
\end{tabular}

a: V: vaginal isolates I-4, R: rectal isolates I-4.

b: Different genotypes are designated A, B, C, D or E per subject. Genotypic similarity/difference only relates to the other isolates of the same subject, i.e. genotype $A$ of subject I does not indicate similarity to genotype $A$ of subject 2.

c: Women for which the genotype of at least one vaginal isolate was identical to that of at least one rectal isolate. 


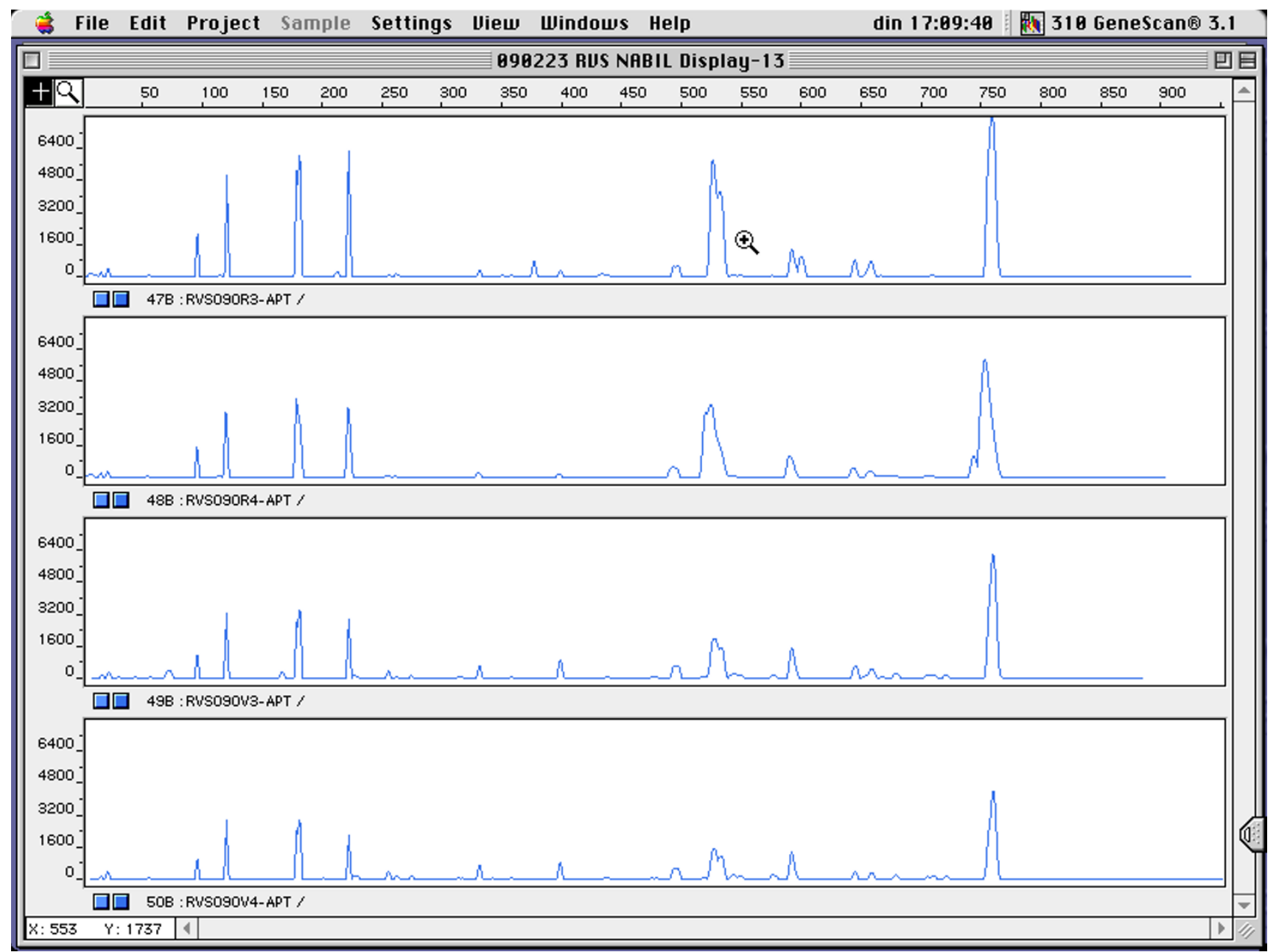

\section{Figure I}

RAPD fingerprints of vaginal and rectal $L$. gasseri isolates of subject RVS090. Vaginal isolates: V3 and V4; rectal isolates: R3 and R4. $x$-axis: length of amplified DNA fragments expressed in bps. $y$-axis: peak height (fluorescence intensity of DNA-fragment as measured by ABI3 10 capillary electrophoresis).

The rectal occurrence of lactobacilli in culture-based studies may be underreported. Because of lactobacilli are the predominant species vaginally, they can be easily overgrown by the predominant rectal bacteria as they represent about $0,01 \%$ of the overall cultivable bacterial intestinal population $[39,40]$. However, high occurrence of intestinal lactobacilli has been reported $[41,42]$. The difference with our study might be explained by the fact that these studies used fecal samples, whereas we started from rectal swabbing.

The virtual absence of $L$. iners from the rectum in this culture-based study is in correspondence with the findings of the other culture-based studies [2,3]. However, preliminary data, obtained by analyzing the same samples using $L$. iners specific realtime PCR, indicate that for most women for which this species could be isolated by culture from the vagina, also the rectal sample is $L$. iners PCR positive (data not reported).

In this population of pregnant women, we isolated lactobacilli more frequently from the vagina (121 subjects, $91.6 \%$ ) than from the rectum (52 subjects, 39.3\%), which is in correspondence with the findings of Antonio et al. [2], who reported vaginal recovery of lactobacilli in $74 \%$ and rectal recovery in $51 \%$ of a total of 531 nonpregnant females.

Although for many women from which lactobacilli could be isolated from the vagina, no lactobacilli were isolated rectally, most of the women that carried lactobacilli rectally, also had vaginal lactobacilli, i.e. few women carried lactobacilli only rectally. 


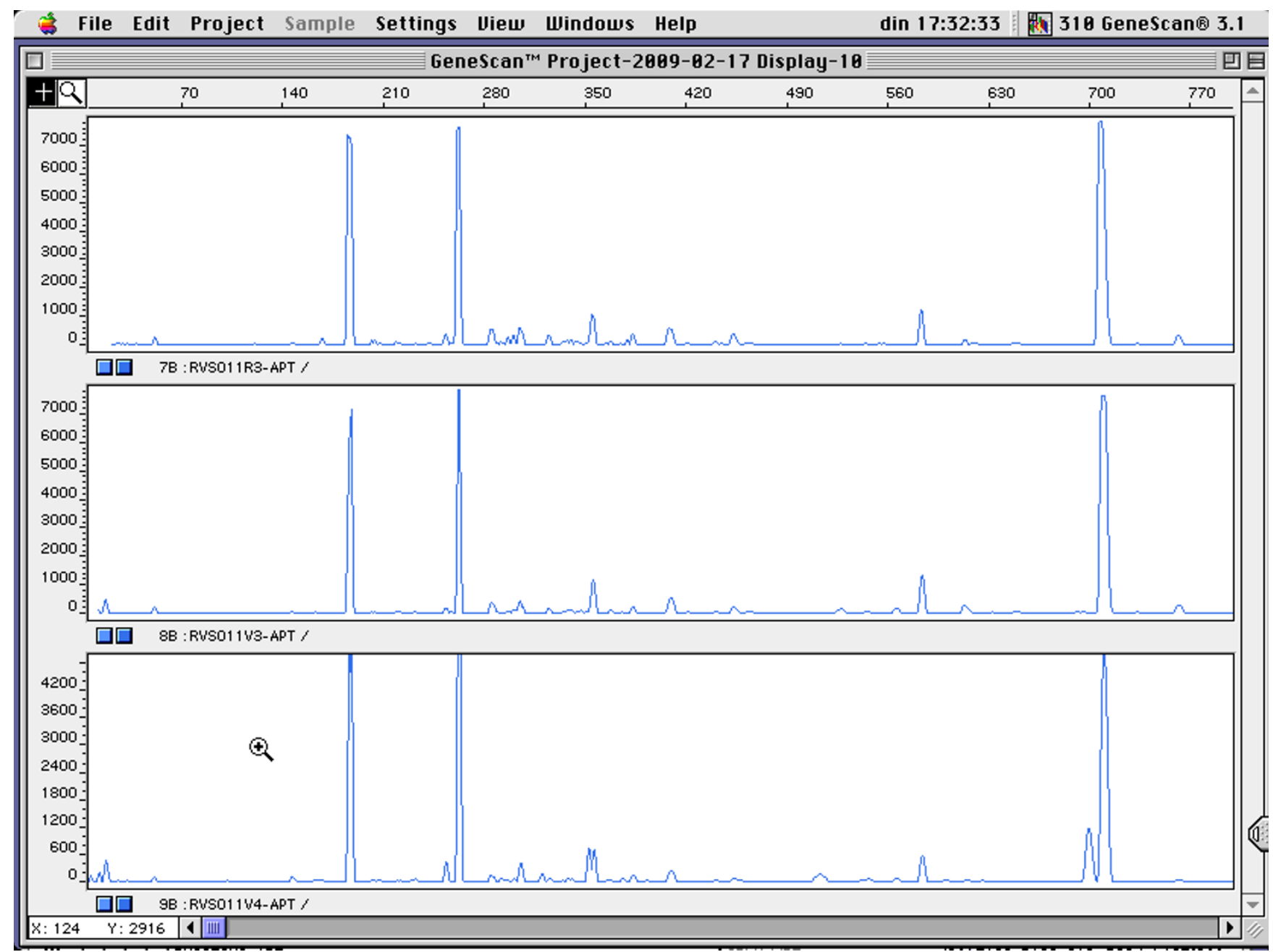

\section{Figure 2}

RAPD fingerprints of vaginal and rectal $L$. crispatus isolates of subject RVSO I I. Vaginal isolates: V3 and V4; rectal isolate: R3. $x$-axis: length of amplified DNA fragments expressed in bps. $y$-axis: peak height (fluorescence intensity of DNA-fragment as measured by ABI3 IO capillary electrophoresis).

\section{Number of Lactobacillus species per individual}

In our study, a total of 46 (35\%) of 132 pregnant women carried two or more Lactobacillus species vaginally and/or rectally. Marrazzo et al. [3] reported $72 \%$ of 237 participants to be colonized overall by lactobacilli and $24 \%$ to be overall colonized with more than one Lactobacillus species. Antonio et al. [6] reported that $8 \%$ carried more than one Lactobacillus species in the vagina.

A total of 18 women in this study were colonized by both L. crispatus and $L$. jensenii (17 vaginally and one rectally). Vaginal colonization of women with $L$. crispatus and $L$. jensenii has been suggested to be advantageous in the maintenance of a normal microflora and the prevention of sexually transmitted diseases $[2,6]$.

\section{Genotyping results: clonal identity between vaginal and rectal isolates}

RAPD was used in this study to detect genotypic similarity of vaginal and rectal strains of the same bacterial species. We could show that for 34 of the 50 pairs (68\%) for which several isolates of the same species were present both in vagina and rectum, genotypic identity could be observed between at least one of the vaginal and at least one of the rectal isolates. In another study, on the same population of women, we compared the genotypes of rectal and vaginal Streptococcus agalactiae (group B streptococci: GBS) isolates and found clonal identity between isolates from both sites in 18 of the 19 subjects [43], confirming that also for GBS the rectally occurring strains are frequently identical to their vaginal counterparts. Because of the close proximity of the rectum to the vagina, the isolation of $\mathrm{H}_{2} \mathrm{O}_{2}$-producing vaginal Lactobacillus species from the 


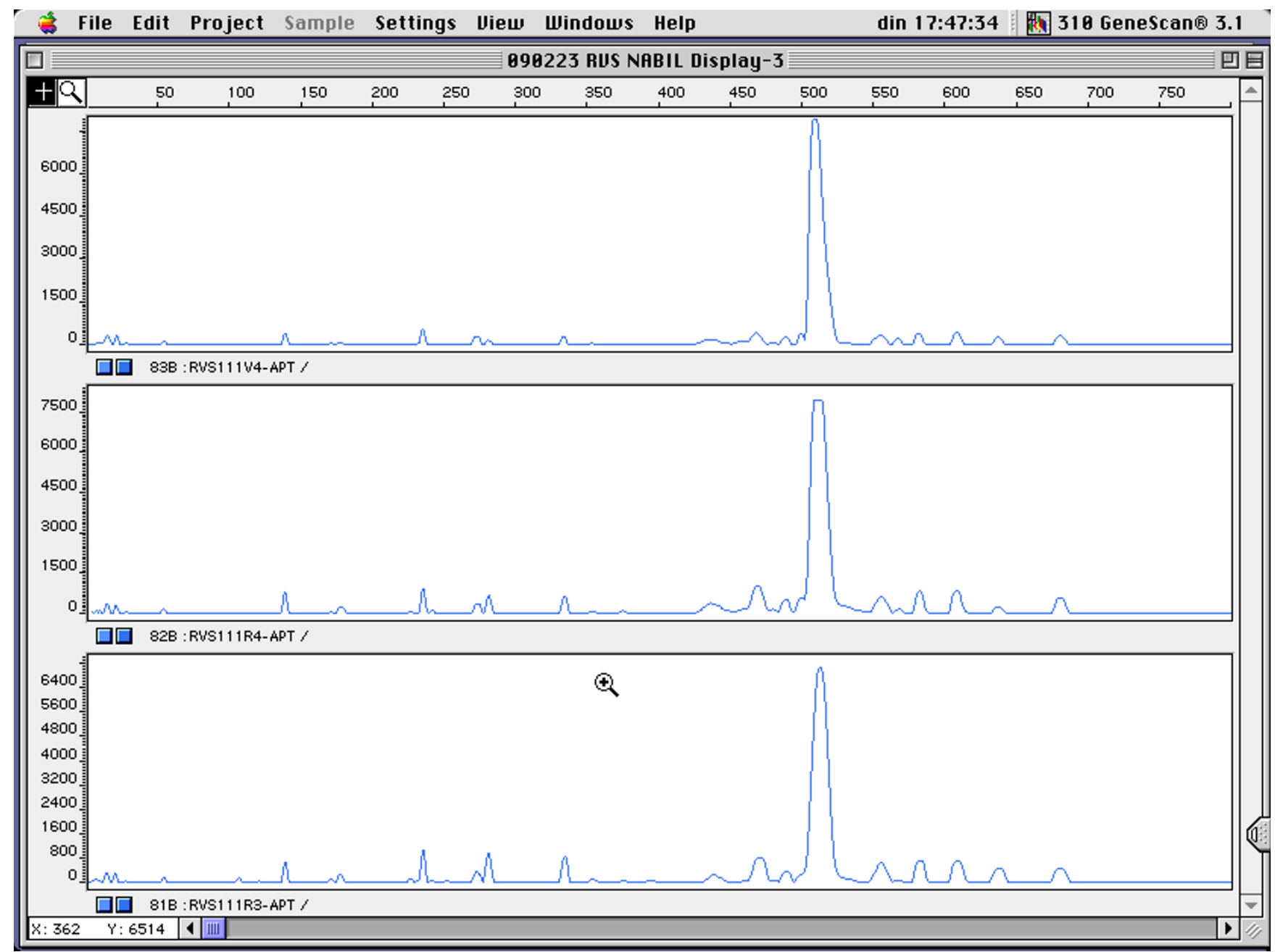

\section{Figure 3}

RAPD fingerprints of vaginal and rectal $L$. jensenii isolates of subject RVSI I I. Vaginal isolate: V4; rectal isolates: R3 and R4. x-axis: length of amplified DNA fragments expressed in bps. $y$-axis: peak height (fluorescence intensity of DNA-fragment as measured by ABI3IO capillary electrophoresis).

rectum suggests that it may play a role as a reservoir for these microorganisms [2].

Vaginal colonization by Lactobacillus species was found to be transient in many females [7], and the rectum may be a source for vaginal recolonisation by lactobacilli after a disturbance of the ecology that follows douching, menses or sexual intercourse. Studies conducted between 1960 and 1980 indicated that while most Lactobacillus strains found in the human intestinal tract are allochthonous, $L$. acidophilus, L. fermentum (now L. reuteri) and $L$. salivarius can be isolated from individuals over longer periods [4448]. Since on the basis of current taxonomy L. crispatus [49], L. gasseri [50] and L. iners [51] belong to the L. acidophilus complex the rectum may be a source for vaginal recolonization by these Lactobacillus species.
Genotyping results: variability among multiple isolates per subject

We found a surprising high genotypic heterogeneity within species. For the 50 species for which isolates were available from both vagina and rectum of a total of 47 pregnant women, on average of 2.2 vaginal respectively 1.3 rectal isolates were genotyped and on average 1.6 vaginal genotypes and 1.1 rectal genotypes were found for these species. It can be expected that more species pairs, more intraspecies genotypic diversity and more identical genotypes in rectum and vagina will be found, when more isolates would be picked. Although we did not sample the same subjects at different time intervals, this finding suggests the occurrence of changes in the composition of the vaginal microflora, whereby different strains of a limited number of species may replace each other, and are may be exchanged between vagina and rectum. 


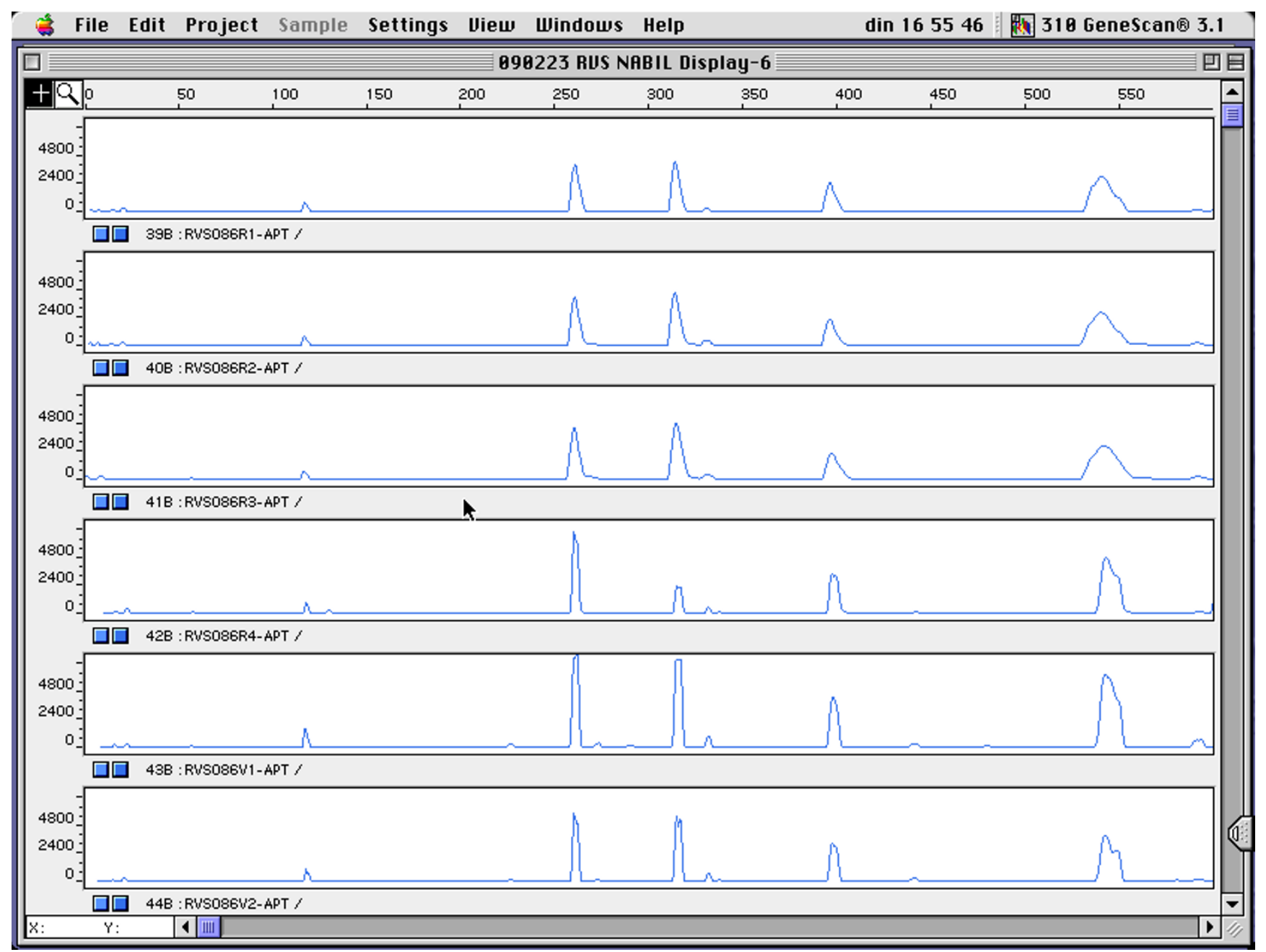

\section{Figure 4}

RAPD fingerprints of vaginal and rectal E. faecalis isolates of subject RVS086. Vaginal isolates: VI and V2; rectal isolates: RI - R4. x-axis: length of amplified DNA fragments expressed in bps. $y$-axis: peak height (fluorescence intensity of DNA-fragment as measured by ABI3 10 capillary electrophoresis).

The high transmissibility of strains was also established in the study of Marrazzo et al. [3] by the observation that many sexual partners carried genotypically identical strains. This hypothesis may be confirmed by long term follow up of individual women, e.g. during subsequent menstrual cycles, and by picking more isolates per subject and per site at multiple time points.

\section{Conclusion}

Although it has been claimed that the vaginal microflora originates from the rectal microflora, this is to our knowledge only the second study, besides the recent study of Marrazzo et al. [3] to address this in detail at the strain level. Several of the total of 63 species identified were found only vaginally $(9$, i.e. $14.3 \%)$ or only rectally $(26$, i.e. $41.3 \%$ ), but 29 species $(44.4 \%)$ were isolated from both sites, indicating that many species can colonize the vagina from the rectum or migrate to the rectum from the vagina. For the 8 species for which isolates were present simultaneously in the same subject in vagina and rectum, we found considerable genotypic diversity within the species (i.e. on average 1.36 genotypes for on average 1.79 isolates per subject), both in rectum and vagina, as well as identical genotypes present simultaneously in rectum and vagina for $70 \%$ of the 50 species pairs studied. All these data indicate a strong correlation between vaginal and rectal microflora, not only at the species level but also at the strain level.

It is possible that the rectal colonization by lactobacilli may function as a reservoir for the maintenance of a normal vaginal flora and that this may be associated with a 
Table 3: Vaginal and rectal occurrence of Lactobacillus species, expressed as percentage of subjects positive, according to different studies

\begin{tabular}{|c|c|c|c|c|c|c|c|c|}
\hline Authors & $\begin{array}{l}\text { Population } \\
\text { studied }\end{array}$ & Species & Vagina only & Vagina alla & $\begin{array}{l}\text { Vagina \& } \\
\text { Rectum }\end{array}$ & Rectum only & Rectum alla & Overall \\
\hline \multirow[t]{5}{*}{ Antonio et al. 1999} & $\begin{array}{l}302 \text { sexually active } \\
\text { women }\end{array}$ & L. crispatus & 32 & & & & & \\
\hline & & L. jensenii & 23 & & & & & \\
\hline & & L. gasseri & 5 & & & & & \\
\hline & & L. iners & 15 & & & & & \\
\hline & & L. vaginalis & $<1$ & & & & & \\
\hline \multirow[t]{5}{*}{ Antonio et al. 2005} & $\begin{array}{l}290 \text { nonpregnant } \\
\text { women }\end{array}$ & L. crispatus & 17 & 31 & 14 & 1 & 15 & 33 \\
\hline & & L. jensenii & 17 & 23 & 6 & 4 & 10 & 27 \\
\hline & & L. gasseri & 3 & 5 & 2 & 8 & 10 & 13 \\
\hline & & L. iners & 15 & 16 & 1 & 0 & 1 & 16 \\
\hline & & L. vaginalis & $<1$ & 0 & 0 & 0 & 0 & 0 \\
\hline \multirow[t]{5}{*}{$\begin{array}{l}\text { Marrazzo et al. } \\
2009\end{array}$} & $\begin{array}{l}237 \text { women having } \\
\text { sex with women }\end{array}$ & L. crispatus & 49 & 93 & 44 & 5 & 49 & 98 \\
\hline & & L. jensenii & 8 & 10 & 2 & I & 3 & 11 \\
\hline & & L. gasseri & 10 & 16 & 6 & 6 & 12 & 21 \\
\hline & & L. iners & 1 & 1 & 0 & 0 & 0 & 1 \\
\hline & & L. vaginalis & 0 & 0 & 0 & 0 & 0 & 0 \\
\hline \multirow[t]{5}{*}{ This study } & I 32 pregnant women & L. crispatus & 33 & 41 & 8 & 3 & 11 & 42 \\
\hline & & L. jensenii & 21 & 32 & 11 & 2 & 13 & 33 \\
\hline & & L. gasseri & 18 & 30 & 12 & 3 & 15 & 33 \\
\hline & & L. iners & 11 & 11 & 0 & 2 & 2 & 12 \\
\hline & & L. vaginalis & 10 & 10 & 0 & 0 & 0 & 10 \\
\hline
\end{tabular}

a: The column entitled 'Vagina all' presents the sum of subjects with the species in the vagina only and those with the species in both vagina and rectum. The column entitled 'Rectum all' presents the sum of subjects with the species in the rectum only and those with the species in both vagina and rectum.

decreased incidence of BV-associated adverse effects, as has been suggested [3].

\section{Competing interests}

The authors declare that they have no competing interests.

\section{Authors' contributions}

$\mathrm{NE}, \mathrm{RV}, \mathrm{GC}$ and MV participated in the development of the study design, the analysis of the study samples, the collection, analysis and interpretation of the data, and in the writing of the report. IT, HV and MT participated in the development of the study design, the collection of the study samples, the collection, analysis and interpretation of the data, and in the writing of the report. BS, PC, GLSS and EDB participated in the analysis of the study samples and interpretation of the data. All authors read and approved the final manuscript.

\section{Acknowledgements}

Nabil Abdullah El Aila is indebted for a PhD Research funded by BOF-DOS of the University of Ghent- Belgium. BOF-DOS was not involved in the development of the study design, the collection, analysis, and interpretation of the data, in the writing of the report nor in the decision to submit the paper for publication.

\section{References}

I. Wilson M: The reproductive system and its indigenous microbiota. In Microbial Inhabitants of Humans: their Ecology and Role in Health and Disease. Cambridge, UK: Cambridge University Press; 2005:206-250.
2. Antonio MA, Rabe LK, Hillier SL: Colonization of the rectum by Lactobacillus species and decreased risk of bacterial vaginosis. J Infect Dis 2005, 1 92(3):394-398.

3. Marrazzo JM, Antonio M, Agnew K, Hillier SL: Distribution of genital Lactobacillus strains shared by female sex partners. J Infect Dis 2009, 199(5):680-683.

4. Klebanoff SJ, Coombs RW: Viricidal effect of Lactobacillus acidophilus on human immunodeficiency virus type I: possible role in heterosexual transmission. I Exp Med |99|, I 74(I):289-292.

5. Song YL, Kato N, Matsumiya Y, Liu CX, Kato H, Watanabe K: Identification of and hydrogen peroxide production by fecal and vaginal lactobacilli isolated from Japanese women and newborn infants. I Clin Microbiol 1999, 37(9):3062-3064.

6. Antonio MA, Hawes SE, Hillier SL: The identification of vaginal Lactobacillus species and the demographic and microbiologic characteristics of women colonized by these species. J Infect Dis 1999, I 80(6): 1950-1956.

7. Vallor AC, Antonio MA, Hawes SE, Hillier SL: Factors associated with acquisition of, or persistent colonization by, vaginal lactobacilli: role of hydrogen peroxide production. J Infect Dis 200I, I84(II): I43I-I436.

8. Verhelst R, Verstraelen H, Claeys G, Verschraegen G, Delanghe J, Van Simaey L, De Ganck C, Temmerman M, Vaneechoutte M: Cloning of I6S rRNA genes amplified from normal and disturbed vaginal microflora suggests a strong association between Atopobium vaginae, Gardnerella vaginalis and bacterial vaginosis. BMC Microbiol 2004, 4:16.

9. Wilks M, Wiggins R, Whiley A, Hennessy E, Warwick S, Porter $\mathrm{H}$, Corfield A, Millar M: Identification and $\mathbf{H}(2) \mathbf{O}(2)$ production of vaginal lactobacilli from pregnant women at high risk of preterm birth and relation with outcome. J Clin Microbiol 2004, 42(2):7|3-7|

10. Hawes SE, Hillier SL, Benedetti J, Stevens CE, Koutsky LA, WolnerHanssen P, Holmes KK: Hydrogen peroxide-producing lactobacilli and acquisition of vaginal infections. I Infect Dis 1996, I74(5): 1058-1063.

II. Martin HL, Richardson BA, Nyange PM, Lavreys L, Hillier SL, Chohan B, Mandaliya K, Ndinya-Achola JO, Bwayo J, Kreiss J: Vaginal lactobacilli, microbial flora, and risk of human immunodeficiency 
virus type I and sexually transmitted disease acquisition. J Infect Dis 1999, I80(6): 1863-1868.

12. Cherpes TL, Meyn LA, Krohn MA, Lurie JG, Hillier SL: Association between acquisition of herpes simplex virus type 2 in women and bacterial vaginosis. Clin Infect Dis 2003, 37(3):319-325.

13. Hillier SL, Nugent RP, Eschenbach DA, Krohn MA, Gibbs RS, Martin DH, Cotch MF, Edelman R, Pastorek JG 2nd, Rao AV, et al.: Association between bacterial vaginosis and preterm delivery of a low-birth-weight infant. The Vaginal Infections and Prematurity Study Group. N Engl J Med 1995, 333(26): 1737- I742.

14. Schrag S, Gorwitz R, Fultz-Butts K, Schuchat A: Prevention of perinatal group $B$ streptococcal disease. Revised guidelines from CDC. MMWR Recomm Rep 2002, 5 I (RR-I I): I-22

15. Ison CA, Hay PE: Validation of a simplified grading of Gram stained vaginal smears for use in genitourinary medicine clinics. Sex Transm Infect 2002, 78(6):4I3-4I5.

16. Verhelst R, Verstraelen H, Claeys G, Verschraegen G, Van Simaey L, De Ganck C, De Backer E, Temmerman M, Vaneechoutte M: Comparison between Gram stain and culture for the characterization of vaginal microflora: definition of a distinct grade that resembles grade I microflora and revised categorization of grade I microflora. BMC Microbiol 2005, 5:61.

17. Baele M, Baele P, Vaneechoutte M, Storms V, Butaye P, Devriese LA Verschraegen G, Gillis M, Haesebrouck F: Application of tRNA intergenic spacer PCR for identification of Enterococcus species. J Clin Microbiol 2000, 38( I I):420 I-4207.

18. Baele M, Storms V, Haesebrouck F, Devriese LA, Gillis M, Verschraegen G, de Baere T, Vaneechoutte M: Application and evaluation of the interlaboratory reproducibility of tRNA intergenic length polymorphism analysis (tDNA-PCR) for identification of Streptococcus species. J Clin Microbiol 200I, 39(4): I436-I 442.

19. Baele M, Vaneechoutte M, Verhelst R, Vancanneyt M, Devriese LA, Haesebrouck F: Identification of Lactobacillus species using tDNA-PCR. Microbiol Methods 2002, 50(3):263-27I.

20. Van Daele S, Vaneechoutte M, De Boeck K, Knoop C, Malfroot A, Lebecque P, Leclercq-Foucart J, Van Schil L, Desager K, De Baets F: Survey of Pseudomonas aeruginosa genotypes in colonised cystic fibrosis patients. Eur Respir J 2006, 28(4):740-747.

21. Zhou X, Bent S], Schneider MG, Davis CC, Islam MR, Forney LJ: Characterization of vaginal microbial communities in adult healthy women using cultivation-independent methods. Microbiology 2004, I 50(Pt 8):2565-2573.

22. De Backer E, Verhelst R, Verstraelen H, Alqumber MA, Burton JP, Tagg JR, Temmerman M, Vaneechoutte M: Quantitative determination by real-time PCR of four vaginal Lactobacillus species, Gardnerella vaginalis and Atopobium vaginae indicates an inverse relationship between $L$. gasseri and $L$. iners. BMC Microbiol 2007, 7: I I5

23. Ferris MJ, Norori J, Zozaya-Hinchliffe M, Martin DH: Cultivationindependent analysis of changes in bacterial vaginosis flora following metronidazole treatment. I Clin Microbiol 2007 45(3): $1016-1018$.

24. Ferris MJ, Masztal A, Martin DH: Use of species-directed I6S rRNA gene PCR primers for detection of Atopobium vaginae in patients with bacterial vaginosis. J Clin Microbiol 2004, 42(I 2):5892-5894.

25. Menard JP, Fenollar F, Henry M, Bretelle F, Raoult D: Molecular quantification of Gardnerella vaginalis and Atopobium vaginae loads to predict bacterial vaginosis. Clin Infect Dis 2008 , 47(I):33-43.

26. Kalra A, Palcu CT, Sobel JD, Akins RA: Bacterial Vaginosis: Culture- and PCR-based Characterizations of a Complex Polymicrobial Disease's Pathobiology. Curr Infect Dis Rep 2007, 9(6):485-500.

27. Srinivasan $S$, Fredricks $D N$ : The human vaginal bacterial biota and bacterial vaginosis. Interdiscip Perspect Infect Dis 2008 2008:750479.

28. Kiss H, Kogler B, Petricevic L, Sauerzapf I, Klayraung S, Domig K, Viernstein $\mathrm{H}$, Kneifel W: Vaginal Lactobacillus microbiota of healthy women in the late first trimester of pregnancy. BJOG 2007, I I 4(I I): | 402-1407.

29. Martinez RC, Franceschini SA, Patta MC, Quintana SM, Nunes AC, Moreira JL, Anukam KC, Reid G, De Martinis EC: Analysis of vaginal lactobacilli from healthy and infected Brazilian women. Appl Environ Microbiol 2008, 74(14):4539-4542.
30. Vasquez A, Jakobsson T, Ahrne S, Forsum U, Molin G: Vaginal lactobacillus flora of healthy Swedish women. J Clin Microbiol 2002, 40(8):2746-2749.

31. Redondo-Lopez V, Cook RL, Sobel JD: Emerging role of lactobacilli in the control and maintenance of the vaginal bacterial microflora. Rev Infect Dis 1990, I 2(5):856-872.

32. Zhou X, Brown C], Abdo Z, Davis CC, Hansmann MA, Joyce P, Foster JA, Forney LJ: Differences in the composition of vaginal microbial communities found in healthy Caucasian and black women. ISME J 2007, I(2): I I I-I 33.

33. McLean NW, Rosenstein IJ: Characterisation and selection of a Lactobacillus species to re-colonise the vagina of women with recurrent bacterial vaginosis. J Med Microbiol 2000 , 49(6):543-552.

34. Reid G, McGroarty JA, Tomeczek L, Bruce AW: Identification and plasmid profiles of Lactobacillus species from the vagina of 100 healthy women. FEMS Immunol Med Microbiol 1996, I5(I):23-26.

35. Kim TK, Thomas SM, Ho M, Sharma S, Reich Cl, Frank JA, Yeater KM, Biggs DR, Nakamura N, Stumpf R, et al.: Heterogeneity of vaginal microbial communities within individuals. J Clin Microbiol 2009, 47(4): $1|8|-1 \mid 89$

36. Burton IP, Cadieux PA, Reid G: Improved understanding of the bacterial vaginal microbiota of women before and after probiotic instillation. Appl Environ Microbiol 2003, 69(I):97-I0I.

37. Hill JE, Goh SH, Money DM, Doyle M, Li A, Crosby WL, Links M, Leung $A$, Chan D, Hemmingsen SM: Characterization of vaginal microflora of healthy, nonpregnant women by chaperonin60 sequence-based methods. Am J Obstet Gynecol 2005, 193(3 Pt I):682-692.

38. Thies FL, Konig W, Konig B: Rapid characterization of the normal and disturbed vaginal microbiota by application of 165 rRNA gene terminal RFLP fingerprinting. J Med Microbiol 2007, 56(Pt 6):755-76I.

39. Sghir A, Gramet G, Suau A, Rochet V, Pochart P, Dore J: Quantification of bacterial groups within human fecal flora by oligonucleotide probe hybridization. Appl Environ Microbiol 2000, 66(5):2263-2266

40. Harmsen HJ, Gibson GR, Elfferich P, Raangs GC, Wildeboer-Veloo AC, Argaiz A, Roberfroid MB, Welling GW: Comparison of viable cell counts and fluorescence in situ hybridization using specific rRNA-based probes for the quantification of human fecal bacteria. FEMS Microbiol Lett 2000, I83(I):I25-I29.

4I. Dal Bello F, Hertel C: Oral cavity as natural reservoir for intestinal lactobacilli. Syst Appl Microbiol 2006, 29(I):69-76.

42. Maukonen J, Matto J, Suihko ML, Saarela M: Intra-individual diversity and similarity of salivary and faecal microbiota. I Med Microbiol 2008, 57(Pt I 2): I560-I568.

43. El Aila NA, Tency I, Claeys G, Saerens B, Verhelst R, De Backer E, Temmerman M, Vaneechoutte M: Genotyping of Streptococcus agalactiae (group B streptococci) isolated from vaginal and rectal swabs of women at 35-37 weeks of pregnancy. $B M C$ Infect Dis 2009, 9(I): 153.

44. Moore WEC, Holdeman LV: Human fecal flora: The normal flora of 20 Japanese-Hawaiians. Appl Microbiol I974, 27:96I-979.

45. Lerche M, Reuter G: Isolierung und Differenzierung anaerober Lactobacillaceae aus dem Darm erwachsener Menschen (Beitrag zum Lactobacillus bifidus-Problem). Zentralbl Bakteriol Parasitenkde Infektionskrankh Hyg Abt I Orig | 96I, I 80:324-356.

46. Reuter G: Das Vorkommen von Laktobazillen in Lebensmitteln und ihr Verhalten im menschlichen Intestinaltrakt. Zentralbl Bakteriol Parasitenkde Infektionskrankh Hyg Abt I Orig 1965, 197:468-487.

47. Mitsuoka T: Vergleichende Untersuchungen über die Laktobazillen aus den Faeces von Menschen, Schweinen, und Hühnern. Zentralbl Bakteriol Parasitenkde Infektionskrankh Hyg Abt I Orig 1969, 210:32-51.

48. Mitsuoka T, Hayakawa K, Kimura N: The fecal flora of man. IIIrd Communication: The composition of Lactobacillus flora of different age groups. Zentralbl Bakteriol Parasitenkde Infektionskrankh Hyg Abt I Orig A 1975, 232:499-5I I.

49. Cato EO, Moore WE, Johnson JL: Synonymy of strains of "Lactobacillus acidophilus " group A2 (Johnson et al. 1980) with the type strain of Lactobacillus crispatus (Brygoo and Aladame 1953) Moore and Holdeman 1970. Bacteriol 1983, 33:426-428. 
50. Lauer E, Kandler O: Lactobacillus gasseri sp. nov., a new species of the subgenus Thermobacterium. Zentralbl Bakteriol MikrobiolHyg Abt I Orig C 1980, I:75-78.

5I. Falsen E, Pascual C, Sjoden B, Ohlen M, Collins MD: Phenotypic and phylogenetic characterization of a novel Lactobacillus species from human sources: description of Lactobacillus iners sp. nov. International Journal of Systematic Bacteriology 1999, 49:217-22I.

\section{Pre-publication history}

The pre-publication history for this paper can be accessed here:

http://www.biomedcentral.com/1471-2334/9/167/pre pub

Publish with Bio Med Central and every scientist can read your work free of charge

"BioMed Central will be the most significant development for disseminating the results of biomedical research in our lifetime."

Sir Paul Nurse, Cancer Research UK

Your research papers will be:

- available free of charge to the entire biomedical community

- peer reviewed and published immediately upon acceptance

- cited in PubMed and archived on PubMed Central

- yours - you keep the copyright

Submit your manuscript here:

http://www.biomedcentral.com/info/publishing_adv.asp
BioMedcentral 